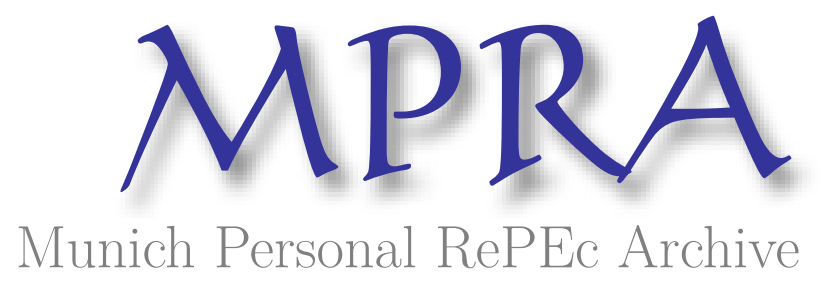

PAPA: An economy-wide general purpose computable general equilibrium model for the Brazilian economy

Guilhoto, Joaquim José Martins

Universidade de São Paulo

1995

Online at https://mpra.ub.uni-muenchen.de/54755/

MPRA Paper No. 54755, posted 27 Mar 2014 15:03 UTC 


\title{
PAPA: An Economy-Wide General Purpose Computable General Equilibrium Model for the Brazilian Economy ${ }^{1}$
}

\author{
Joaquim J.M. Guilhoto²
}

\begin{abstract}
In this paper the PAPA model, constructed for the Brazilian economy, is described as well as some simulations of policies made with this model. The PAPA model is a Computable General Equilibrium (CGE) model of the Johansen type and the solutions of the model are given in growth rates. This model is based on the ORANI model constructed for the Australian economy and in that sense it is a general purpose model that can be used to study the impact of different economic policies on the Brazilian economy.

The model is defined for: a) 33 types of industries/commodities; b) 3 types of primary factors; c) 3 categories of labor; d) 2 sources of products (domestic, and imported); e) 5 types of product use; and, f) 3 income groups.
\end{abstract}

\section{Introduction}

The PAPA model constructed for the Brazilian economy is a Computable General Equilibrium (CGE) model of the Johansen type (see Johansen, 1974) and the solutions of the model are given in growth rates. This model, described in full in Guilhoto (1995), is based on Guilhoto(1986) which in its turn is based on the ORANI model constructed for the Australian economy (see, Dixon et. al., 1982) and in that sense it is a general purpose model that can be used to study the impact of different economic policies on the Brazilian economy.

The main differences from the ORANI model and the one presented here are: a) the present model breaks down the demand for household consumption by different income groups, and introduces an equation linking the workers income with their expenditures, allowing, in this

\footnotetext{
${ }^{1}$ The author wishes to thank the valuables comments of Geoffrey J.D. Hewings in a previous version of this paper.

2 ESALQ - University of São Paulo, Brazil and REAL, University of Illinois.

The support provided by FAPESP and by REAL (University of Illinois) is gratefully acknowledged.
} 
way, for the study of income distribution problems; and b) the model presented here assumes that each industry produces only one type of commodity, in contrast to the ORANI model that uses a more general industry by commodity framework.

The results of the model are given in percentage changes, which can be interpreted in the following way: for a given policy change $A$, in the macroeconomic environment $B$, variable $C$ will differ in the short run by $x$ percent from the value it would have had in the absence of the policy change; in the long run it will differ by $y$ percent. Thus the model involves a comparative static analysis. The difference between the short- and the long-run is that in the long-run capital stocks are allowed to change. The results for the model are not given for a specific period of time, but for the time necessary for the variables to adjust themselves to a new from an old equilibrium position that was disrupted by a given policy change $A$.

To derive the equations for the model, one starts from equations in level form and then derives the percentage-change form for this equation. In doing so, one will get a linear system of equations in which the number of variables will be greater than the number of equations. In using the model, some of the variables will have to be made exogenous to solve the system. The choice of what is exogenous or endogenous will vary according to the uses to which the model will be put; however, the choice does involve considerable judgment and is not without problems (for a discussion of closure, see below).

The paper is organized in the following way; section 2 presents the main characteristics of the model, while sections 3 and 4 discuss respectively the methods used in solving and closing the model. Two simulations with the model are presented in section 5, and final comments complete the paper. 
Table 1

\section{Block Equations of the Model}

\section{Final Demand}

Household demands for commodities classified by source

General price of each commodity to households

Household demands for commodities, by income group, undifferentiated by source

Budget Constraint for the household in each income group

Export demand functions

Government and "other" demands for commodities classified by source

Real household expenditure

Demands for margins to facilitate commodity flows to households

Demands for margins to facilitate commodity flows for ports prior to export

Demands for margins to facilitate commodity flows for government and "other" demands

\section{Production}

\begin{tabular}{l}
\hline Demand for intermediate inputs, domestic and imported \\
\hline Demands for labor by industry and skill group \\
\hline Industry demands for primary factors \\
\hline Price to each industry of labor in general \\
\hline Demands for "other costs" \\
\hline Demand for intermediate inputs to capital creators, domestic and imported \\
\hline Demands for margins to facilitate commodity flows to producers and capital creators \\
\hline Weighted sums of the technical-change terms affecting the production functions of each industry \\
\hline Supply of commodities by industries \\
\hline Rates of return on capital in each industry \\
\hline Equality of rates of return across industries \\
\hline Capital accumulation \\
\hline Investment budget \\
\hline Equations for handling exogenous investment \\
\hline Real private investment expenditure
\end{tabular}


Table 1 (Continued)

\section{Block Equations of the Model}

\section{Market Clearing}

Demand equals supply for domestically produced commodities

Demand equals supply for labor of each skill

Demand equals supply for capital

Demand equals supply for agricultural land

\section{Price System}

Zero pure profits in production

Zero pure profits in capital creation

Zero pure profits in importing

Flexible handling of tariff rates

Zero pure profits in exporting

Flexible handling of exports taxes (subsidies)

Zero pure profits in the distribution of goods to producers and capital creators

Zero pure profits in the distribution of goods to households

Flexible handling of taxes (subsidies) to producers and capital creators

Flexible handling of taxes (subsidies) to households

\section{External Market}

\begin{tabular}{l}
\hline Import volumes \\
\hline Foreign currency value of imports \\
\hline Foreign currency value of exports \\
\hline The balance of trade \\
\hline
\end{tabular}

\section{Economic Indexes}

\begin{tabular}{l}
\hline Consumer price index \\
\hline Capital goods price index \\
\hline Aggregate employment \\
\hline Aggregate capital stock \\
\hline Ratio of real investment to real consumption \\
\hline Flexible handling of wages by occupation and industry \\
\hline Indexing of the prices of "other costs" \\
\hline \hline
\end{tabular}




\section{Model Description}

In the PAPA model equations are derived for industry demands, final demands, prices, investment allocation, market-clearing, and miscellaneous definitions ${ }^{3}$. The original system of equations is made of 19520 equations, and 40986 variables, to make it into a workable size, the original system was reduced to a system of 6452 equations and 8316 variables ${ }^{4}$.

The system of equations of the model, presented into Table 1, can be divided into the following blocks: Final Demand, Production, Market Clearing, Price System, External Market, and Economic Indexes. This set of equations can give an idea of the size and capabilities of the model.

Table 2

\section{Industries/Commodities Defined in the Model}

\begin{tabular}{clcl}
\hline Industry & Description & Industry & Description \\
\hline 1 & Forestry & 18 & Clothing and Footwear \\
\hline 2 & Coffee & 19 & Coffee Industry \\
\hline 3 & Sugar Cane & 20 & Rice Industry \\
\hline 4 & Rice & 21 & Wheat Industry \\
\hline 5 & Wheat and Soybean & 22 & Meat Cattle Industry \\
\hline 6 & Poultry & 23 & Poultry Industry \\
\hline 7 & Meat and Milk Cattle & 24 & Dairy Industry \\
\hline 8 & Other Agricultural Products & 25 & Sugar and Alcohol Industry \\
\hline 9 & Mining & 26 & Vegetable Oil \\
\hline 10 & Metallurgy & 27 & Feeding Stuff for Animal \\
\hline 11 & Machinery & 28 & Other Food Industries \\
\hline 12 & Electrical Equipment & 29 & Miscellaneous Industries \\
\hline 13 & Transport Equipment & 30 & Public Utilities \\
\hline 14 & Wood, Wood Products, Paper Products, and & 31 & Construction \\
\hline 15 & Printing & & \\
\hline 16 & Fertilizers & 32 & Trade and Transportation \\
\hline 17 & Textiles & 33 & Services \\
\hline
\end{tabular}

\footnotetext{
${ }^{3}$ For a complete description of the equation system see Guilhoto (1995).

4 The model was solved using the GEMPACK program.
} 
The system of equations in the PAPA model is defined for:

1) 33 types of industries/commodities (Table 2);

2) 3 types of primary factor:
a) 3 categories of labor;
b) fixed capital (building, plant and machinery);
c) agricultural land;

3) "other costs" (production taxes, costs of holding liquidities, cost of holding inventories, and other miscellaneous costs);

4) 2 sources of products:
a) Domestic;
b) Imported;

5) 5 types of product use:
a) inputs to current production;
b) inputs to capital formation;
c) commodity flows to household consumption;
d) exports;
e) government and "other" demands;

6) 3 income groups.

The original set of input-output tables used in the model are for the year of 1980. A complete description of the data set used in the construction of the PAPA set is found in chapter 5 of Guilhoto(1995).

In the next section its is made a discussion of the ways that can be used to solve the PAPA model.

\section{Solving the Model}

Following Pearson and Rimmer (1983) the equations of a CGE model can be written as:

$$
F \mathbf{a I}=F \mathbf{M}, z_{2} \mathbf{g}_{0}
$$


where $\mathrm{F}$, in general, is a non-linear function, $Z$ is a vector of variables, $Z_{1}$ is a partition of vector $Z$ with the endogenous variables, and $Z_{2}$ is a partition of vector $Z$ with the exogenous variables.

In the Johansen-type models, which is the case of the PAPA model, the resolution of the system is done by first linearizing F, near a know solution of (1), in terms of percentage changes in the variables $Z$. Equation (1) is then replaced by the following matrix equation

$$
D z=0
$$

where $\mathrm{z}$ is a vector of percentage change and $D$ is an $m x n$ matrix.

In general

$$
n>m
$$

so that values for $(n-m)$ components of $z$ must be set exogenously, and (2) may be solved to obtain values for the remaining variables. $z$ can be partitioned into a vector $z_{2}$ of exogenous variables, and a vector $z_{1}$ of endogenous variables, then (2) can be written as:

$$
A z_{1}=-B z_{2}
$$

where $A$ is an $m \times m$ matrix, $z_{1}$ is $m \times 1, B$ is $m \times p(p=n-m)$ and $z_{2}$ is $p \times 1$. The solution for the model is then giving by:

$$
z_{1}=-A^{-1} B z_{2}
$$

So, a Johansen type model can be solved only with matrix algebra (this kind of solution receives the name of Johansen method in the GEMPACK program). However, in the process of linearization, of the initial system, errors occurred, and the result given in (4) is only an approximation of the true result. As a way of reducing the errors created by the linearization, there are some numerical methods that can be used to get better results, in the case of the 
GEMPACK program there is the possibility of using the Euler, Gragg, and Midpoint methods which are presented below. ${ }^{5}$

The Euler, Gragg, and Midpoint methods are methods of multi-step simulations, i.e., given a shock it is divided into smaller ones, and in each step the linearized equations are solved for these smaller shocks. After each step, a new point of equilibrium is found and the coefficients and parameters of the model are recalculated. In general, the more the number of steps, the greater the precision of the results.

Figure 1 allows for a illustration of the methods described above. For presentation purpose, we are considering only one exogenous $(X)$ and one endogenous $(Y)$ variable. The real shape of the function to be linearized is given by the curve $g \mathbf{d}, Y \mathbf{T}=0$, where $A$ is the point that is going to receive the initial shock, given by the change in the exogenous variable from $X_{0}$ to $X_{1}$.

At the point $X_{1}$ the real value of the function is given by $Y_{1}$, if the method used for the solution was the Johansen method, the result is given in point $C$ where the value of the exogenous variable is given by $Y_{J}$, giving the linearization error in the interval $B C$. In the Euler's method, with 2 steps, the first solution is given in point $D$ where one has a new point of equilibrium, and the system receives the second shock, which gives a final value of $Y_{E}$ for the endogenous variable, and the linearization error is giving now by the interval $B E$, smaller than $B C$. In the cases of the Midpoint and Gragg methods, the first step is identical to the Euler's method. The difference is that in the second step, while the Euler method follows the tangent starting at point $D$, the other methods follow the same direction, but they started in the previous point, as can be seen in Figure 1, the segment $A F$ is parallel to the segment $D E$, giving the value $Y_{M}$ for the endogenous variable, with the linearization error giving by $B F$, smaller than the one presented by the Johansen and Euler methods.

\footnotetext{
5 The remaining of the discussion in this section is based in Harrison and Pearson (1994a e 1994b). A more detailed treatment of the theory is presented in Atkinson (1989), while discussions of utilization of these methods in CGE models can be found in Rimmer (1981), Dixon et. al. (1982), Pearson and Rimmer (1983), Pearson (1991), and Dixon et. al. (1992).
} 
Figure 1

\section{Solution Methods of GEMPACK Program}

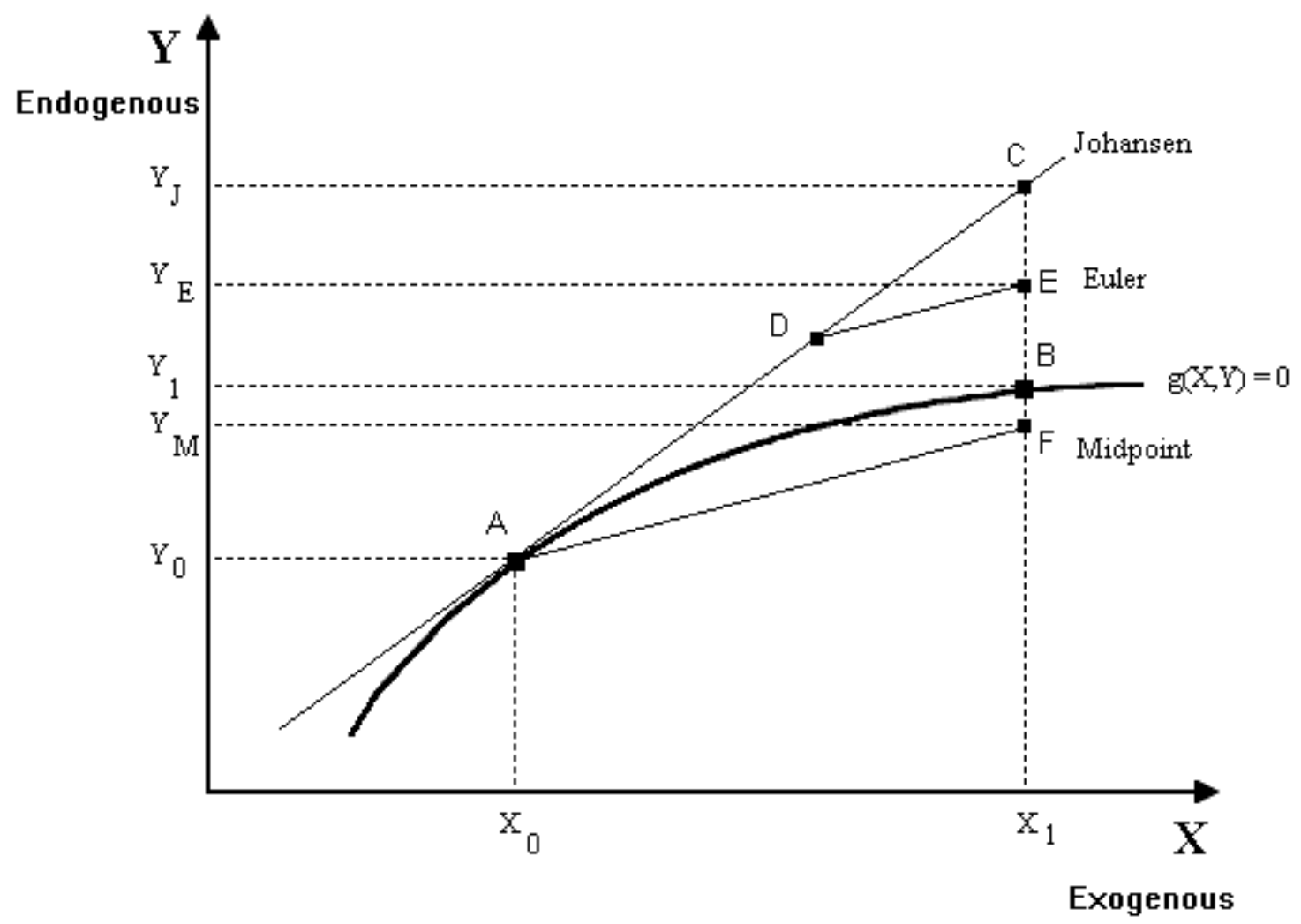

The Gragg and Midpoint methods are similar, the difference being that the Gragg does one more step. If one chooses $n$ steps, the Midpoint does $n$ steps, while the Gragg does $(n+1)$, the Gragg method starts near the final point and takes the exogenous variable past its end point. This is done to obtain a correction to the result after $n$ steps, giving in general, a much more precise result than the one that is obtained when it is used only $n$ steps.

Following Harrison and Pearson (1994b, p. 5-3):

"Our experience is that, provided your simulation is not too nonlinear, Gragg or midpoint will converge significantly faster than Euler and that the extra accuracy Gragg usually gets from the extra pass it does compared to the midpoint method is usually well worth the extra time taken. However, we have found that in some 
highly nonlinear simulations, Gragg and midpoint diverge rapidly. If this happens, ..., you should try Euler's method (though that may not converge either in these cases)".

As mentioned early as you increase the number of steps the precision of the results tends to increase. But, a greater number of steps requires more time of computation, and sometimes this time is not available. A way of increasing the precision of the results, and at the same time to reduce the time needed to get the solution for the model is to extrapolate the results of 2 or 3 simulations with different number of steps. The extrapolation is done through a weighted average of the results of these simulations.

Experience with the PAPA model shows that the results obtained with the Euler, Gragg, and Midpoint methods do not differ much among themselves. But given that the Gragg method seems to be the one who gives the more accurate results, it is wise to use this method with the extrapolation of the results obtained in 2, 4, and 6 steps.

The next section presents a discussion of options that can be used for closing the PAPA model.

\section{Closing the Model}

Giving the way that the model was constructed, it allows for flexibility in choosing between endogenous and exogenous variables, i. e., flexibility in choosing the way that the model is going to be closed. But, despite this flexibility, the choice of the set of endogenous and exogenous variables can not be done in a random way, in general variables that are not explained by equations in the model should be set exogenous. An overview of how to close the model is given by Dixon, et.al. (1982, p.148):

"It is not true that the model can be closed by the exogenous setting of any $p$ variables. For example, at least one monetary variable should be included in the exogenous list... Similarly, some care is necessary to avoid inconsistencies. ... Although we can offer no formal theory to guide the model 
users in their choice of exogenous variables, as a working rule, if a price appears on the exogenous list, then a corresponding quantity should be on the endogenous list and vice versa. If wages are exogenous, then employment will be endogenous; if export taxes are endogenous, then export volumes will be exogenous; if tariffs are exogenous, then imports will be endogenous; and if sales taxes are endogenous, then consumption will be exogenous"

The model can be closed such that results can be given for the short- or for the long-run period. In the short-run closure, the vector of capital stocks is exogenous to the system. In the long-run closure it is endogenous to the system, and either the vector of the rates of return or the vector of rentals on capital becomes exogenous to the system.

Further discussion about closure in the ORANI model, and that can be applied to a better understanding of how to close the PAPA model, can be found in Cooper and McLaren (1980 and 1981), Powell, Cooper, and McLaren (1983), Cronin (1985), and Powell (1985).

The experience of working with the PAPA model shows that it is possible to define a basic set of exogenous variables, that help in choosing the way that the model is going to be closed. This list of variables is presented in Chapter 6 of Guilhoto (1995), which also presents a more detailed presentation of how to close the PAPA model.

Two simulations with the PAPA model are presented in the next section.

\section{Simulations with the Model}

As a way of showing the capability of the PAPA model this section presents the results of two simulations. The first one, impact of a $25 \%$ across-the-board tariff increase, allows for a comparison of the results from the PAPA model with the ones presented from the ORANI model for the Australian economy (Dixon et.al., 1982). The other simulation measures the impact of a $10 \%$ increase in the exports of selected Agricultural/Food Industry Industries. 
The results of the simulations presented here were obtained with the utilization of the Gragg method with extrapolated results for the simulations of 2, 4, and 6 steps. $^{6}$

Due to the great number of endogenous variables in the model, the results presented here are only for a key set of variables needed for a better understanding of the simulations results, as well as of the capability of analysis of the PAPA model.

The numeraire in both simulations is the exchange rate.

\subsection{Impact of a $25 \%$ Across-the-Board Tariff Increase}

In this simulation it is made a $25 \%$ across-the-board tariff increase, so one can compare the results obtained in the PAPA model with the ones from the ORANI model.

Despite the fact that the closure presented by the PAPA model being similar to the ORANI model (see chapter 7 of Dixon et.al., 1982), due to the particularities of the models and economies, there are some differences:

1. The variable that represents the real aggregate household expenditure is exogenous in the ORANI model and endogenous in the PAPA model;

2. In the PAPA model there is a variable that represents the aggregate residual value (income less consumption) in each income group, while there is not such a variable in the ORANI model;

3. In the closure of the ORANI model there are two sets of goods: a) the one to which the exports are endogenous to the model; and b) the one where exports are exogenous to the model and ORANI projects the value of taxes (subsidies) needed to get this level of exports. In the PAPA simulation it is assumed that all the exports levels are endogenous to the model an there is not any change in the value of taxes (subsidies) for exports;

\footnotetext{
${ }^{6}$ In the case of the first simulation, caparison with the ORANI model, one also gets results for the Johansen method.
} 
4. In the PAPA model all taxes and tariffs are treated as ad valorem; while in the ORANI model tariffs are treated as ad valorem, and export and sales taxes are treated as specific in real terms.

Table 3

\section{Comparison of the Results from the ORANI and PAPA Models}

\section{Impact of a $25 \%$ Across-the-Board Tariff Increase}

\begin{tabular}{lrrrr}
\hline \multicolumn{1}{c}{ Description } & ORANI & PAPA & $\begin{array}{c}\text { ORANI } \\
\text { Euler } \\
\text { Johansen }\end{array}$ & $\begin{array}{c}\text { PAPA } \\
\text { Gragg }\end{array}$ \\
& Johansen & $\mathbf{4}, \mathbf{e}$ 6 \\
\hline Aggregate employment & $-0,20546$ & $-1,25511$ & $-0,20086$ & $-1,21861$ \\
\hline ORANI - Professional white collar & $-0,13391$ & - & $-0,12960$ & - \\
\hline ORANI - Skilled white collar & $-0,05866$ & - & $-0,05791$ & - \\
\hline ORANI - Semi and unskilled white collar & $-0,09383$ & - & $-0,09222$ & - \\
\hline ORANI - Skilled blue collar (metal and electrical) & $-0,00343$ & - & $-0,00268$ & - \\
\hline ORANI - Skilled blue collar (building) & 0,10584 & - & 0,10798 & - \\
\hline ORANI - Skilled blue collar (other) & 0,01889 & - & 0,00830 & - \\
\hline ORANI - Semi and unskilled blue collar & $-0,12293$ & - & $-0,12167$ & - \\
\hline ORANI - Rural workers & $-2,08587$ & - & $-2,02952$ & - \\
\hline ORANI - Armed services & $-0,00000$ & - & $-0,00000$ & - \\
\hline PAPA - Workers who receive between 0 and 5 minimum wages & - & $-1,23926$ & - & $-1,20271$ \\
\hline PAPA - Workers who receive between 5 and 20 min. wages & - & $-1,27180$ & - & $-1,23462$ \\
\hline PAPA - Workers who receive + 20 minimum wages & - & $-1,24836$ & - & $-1,21289$ \\
\hline Aggregate exports (foreign currency value) & $-2,52378$ & $-2,60208$ & $-2,46329$ & $-2,52663$ \\
\hline Aggregate imports (foreign currency value) & $-1,52702$ & $-1,22601$ & $-1,44205$ & $-1,18419$ \\
\hline Balance of trade & $-31,68000$ & $-14278,61$ & $-33,16000$ & $-13855,16$ \\
\hline Index of consumer prices & 2,20004 & 0,31311 & 2,17777 & 0,31525 \\
\hline Capital-goods price index & 2,75364 & 0,46063 & 2,73256 & 0,45934 \\
\hline Real aggregate household expenditure ${ }^{*}$ & 0,00000 & $-1,25272$ & 0,00000 & $-1,21620$ \\
\hline
\end{tabular}

* This variable is exogenous in the ORANI model, and endogenous in the PAPA model.

Source: ORANI Model: Dixon et. al. (1982); PAPA Model: Guilhoto (1995).

Despite this differences, one believes that the simulations in the two models can be compared, so one can get a idea of the differences between the two models and the two economies. 
In comparing the models, it was also made a comparison of the solution methods used in solving them. The ORANI model shows results for the Johansen method and for the Euler method with the results extrapolated from 4 and 8 steps (which is assumed that the results are free from linearization errors), while the PAPA model shows results for the Johansen method and for the Gragg method with the results extrapolated from 2,4, and 6 steps (which is assumed that the results are free from linearization errors).

The results, for selected variables, from the simulations of the ORANI and PAPA models are presented in Table 3.

The results show that in the two models there is a fall in the aggregate employment, in the aggregate exports and imports, and in the balance of trade. The fall in the aggregate employment is greater in the Brazilian economy than in the Australian, while the price impacts are greater in the Australian economy. These results suggest a more tight situation in the possibilities of imports in the Brazilian economy than in the Australian economy, i.e., in the Brazilian economy there is not much substitutability between the imported and the domestic goods.

In the Australian economy, the increase in tariffs will generate an increase in the demand for domestic goods, which in turns led to an increase in the production and in the prices of these goods, followed by a fall in the level of demand, this will repeat itself until the system goes to a point of equilibrium. At the end, the substitution of imported goods by domestic goods will led to a equilibrium point were the fall in the aggregate employment is smaller in the Australian economy than it is in the Brazilian economy.

The ORANI model, as well as the PAPA model, show differences in the results due to the solution method used. What suggests that in the first moment one should use the Johansen method to test the sensibility of the model to the set of exogenous and endogenous variables, and after that use the Gragg method, for example, to obtain the final result of the simulation. 


\subsection{Impact of a $10 \%$ Increase in the Exports of Selected Agricultural/Food Industry}

\section{Industries}

In the simulation presented here there is an increase in $10 \%$ in the exports of the following industries:

- Wheat and Soybean

- Coffee Industry

- Meat Cattle Industry

- Poultry Industry

- Sugar and Alcohol Industry

- Vegetable Oil

- Feeding Stuff for Animal

Table 4.A

Impact of a $10 \%$ Increase in the Exports of Selected Agricultural/Food Industry Industries

\begin{tabular}{lr}
\hline \multicolumn{1}{c}{ Description } & Projection \\
\hline Aggregate employment & 0,371643 \\
\hline PAPA - Workers who receive between 0 and 5 minimum wages & 0,313776 \\
\hline PAPA - Workers who receive between 5 and 20 min. wages & 0,385419 \\
\hline PAPA - Workers who receive + 20 minimum wages & 0,416768 \\
\hline Aggregate exports (foreign currency value) & 1,379990 \\
\hline Aggregate imports (foreign currency value) & 0,246205 \\
\hline Balance of trade & 13506,90 \\
\hline Index of consumer prices & 0,238404 \\
\hline Capital-goods price index & 0,208709 \\
\hline Real aggregate household expenditure & 0,362664 \\
\hline $\begin{array}{l}\text { Aggregate household expenditure - in the income group who receives } \\
\text { between 0 and 5 minimum wages }\end{array}$ & 0,552928 \\
\hline $\begin{array}{l}\text { Aggregate household expenditure - in the income group who receives } \\
\text { between 5 and 20 minimum wages }\end{array}$ & 0,624742 \\
\hline $\begin{array}{l}\text { Aggregate household expenditure - in the income group who receives more } \\
\text { than 20 minimum wages }\end{array}$ & 0,656166 \\
\hline Economy-wide expected rate of return on capital & 0,591489 \\
\hline Aggregate private investment expenditure & 0,208709 \\
\hline & \\
\hline
\end{tabular}


Table 4.B

\section{Impact of a $10 \%$ Increase in the Exports of Selected}

Agricultural/Food Industry Industries

\begin{tabular}{lrrr}
\hline \multicolumn{1}{c}{ Industry } & Production & Export & Import \\
\hline 1. Forestry & 0,201695 & $-4,591210$ & 0,184900 \\
\hline 2. Coffee & 4,581240 & $-6,767640$ & 1,107490 \\
\hline 3. Sugar Cane & 1,784130 & $-5,599750$ & 0,662023 \\
\hline 4. Rice & 0,316312 & $-4,479280$ & 0,815432 \\
\hline 5. Wheat and Soybean & 3,969880 & 10,000000 & 0,798326 \\
\hline 6. Poultry & 0,861004 & $-5,788600$ & 1,407610 \\
\hline 7. Meat and Milk Cattle & 0,683538 & $-6,229310$ & 0,633727 \\
\hline 8. Other Agricultural Products & 0,593839 & $-5,178220$ & 0,785308 \\
\hline 9. Mining & 0,041872 & $-0,011284$ & 0,174899 \\
\hline 10. Metallurgy & $-0,007597$ & $-0,063631$ & $-0,051905$ \\
\hline 11. Machinery & $-0,301551$ & $-4,059920$ & $-0,015034$ \\
\hline 12. Electrical Equipment & $-0,219887$ & $-3,783540$ & 0,040169 \\
\hline 13. Transport Equipment & $-0,296926$ & $-3,860640$ & 0,039653 \\
\hline 14. Wood, Wood Products, Paper Products, and Printing & 0,238222 & $-0,071763$ & 0,223900 \\
\hline 15. Chemicals & 0,178782 & $-2,665110$ & 0,390389 \\
\hline 16. Fertilizers & 1,534890 & $-3,009570$ & 1,495000 \\
\hline 17. Textiles & 0,002821 & $-4,277990$ & 0,065658 \\
\hline 18. Clothing and Footwear & 0,405150 & $-0,076034$ & 0,397429 \\
\hline 19. Coffee Industry & 5,974510 & 10,000000 & 0,194923 \\
\hline 20. Rice Industry & 0,222523 & $-4,867180$ & 0,219212 \\
\hline 21. Wheat Industry & 0,374020 & $-4,306560$ & 0,396448 \\
\hline 22. Meat Cattle Industry & 0,882198 & 10,000000 & 0,704534 \\
\hline 23. Poultry Industry & 1,737230 & 10,000000 & 0,650997 \\
\hline 24. Dairy Industry & 0,328146 & $-5,233860$ & 0,345596 \\
\hline 25. Sugar and Alcohol Industry & 2,035860 & 10,000000 & 0,313739 \\
\hline 26. Vegetable Oil & 4,990750 & 10,000000 & 1,570950 \\
\hline 27. Feeding Stuff for Animal & 1,051830 & 10,000000 & 0,732623 \\
\hline 28. Other Food Industries & 0,240530 & $-0,175204$ & 0,276399 \\
\hline 29. Miscellaneous Industries & 0,011226 & $-3,934360$ & 0,121961 \\
\hline 30. Public Utilities & 0,265938 & $-4,851620$ & 0,274519 \\
\hline 31. Construction & $-0,022434$ & $-4,286480$ & 0,717658 \\
\hline 32. Trade and Transportation & 0,334914 & $-4,437940$ & 0,334152 \\
\hline 33. Services & 0,339638 & $-4,843870$ & 0,343995 \\
\hline Source: Guilhoto (1995) & & & \\
\hline \hline & & & \\
\hline
\end{tabular}


The increase in the exports of these industries, without the respective increase in prices, means that there was a shift in the demand curves for the exports of these industries. As can be seen in Table 4.A, the increase in exports is followed by an increase in the level of the economic activity, with and increase in level of imports (smaller than the increase in exports). From Table 4.B one gets that despite the fact that the level of exports decreased in all the other industries but the ones that are receiving the impact, the aggregate volume of exports increased.

There is an increase in the production level as a whole, where the decreased in the production level of the industries who produce durable and capital goods is more than compensated by the increase in the agricultural / food industry industries.

The last section presents some final remarks about the PAPA model.

\section{Conclusions}

In this paper it was presented an overview of the PAPA model, where the main characteristics of the model were presented, as well as two simulations made with the model.

From the above presentation one can see that the PAPA model is working and giving consistent results for the Brazilian economy, but, there is still much work to be done, among other things, the PAPA model could benefit from:

- A better and more updated set of elasticities (still to be estimated);

- The utilization of a more recent set of input-output matrices (still to come out);

- The specification of the labor type by occupation and not by income group;

- A more detailed treatment of the investment in the model.

The PAPA model, like the ORANI model, is a very flexible model, in the sense that, among other possibilities:

- It is possible to add a regional dimension to it;

- It can be linked with a demographic model; 
- It can be linked with a macroeconometric model;

- The external industry of the model can be divided into different economic blocks in a sense that one could study the impact of different trade policies with the different economic block on the Brazilian economy .

In summary, despite the problems that the PAPA model presents, one believes that is potentialities are great. The first step, the construction of the model, has already been done, and what is need now, it is a continuous work of correcting the problems and improving the PAPA model such that one can get better and more accurate results for the Brazilian economy. 


\section{REFERENCES}

Atkinson, K.E. (1989). An Introduction to Numerical Analysis. Second Edition. New York: Wiley.

Cooper, R.J., and K.R. McLaren (1980). "The ORANI-MACRO Interface." Impact Project Preliminary Working Paper. N. IP-10.

Cooper, R.J., and K.R. Mclaren (1981). "The ORANI-MACRO Interface: An Illustrative Exposition." Impact Project Preliminary Working Paper. N. IP-13. Also in The Economic Record. 59 (165): 166-179, June, 1983.

Cronin, M. R. (1985). "The ORANI Model in Short Run Mode: Theory Versus Observation." Australian Economic Papers. 24, June, pp. 24-36.

Dixon, P.B., B.R. Parmenter, A.A. Powell, and P.J. Wilcoxen (1992). Notes and Problems in Applied General Equilibrium Economics. Amsterdam: North-Holland.

Dixon, P.B., B.R. Parmenter, J. Sutton, and D.P. Vincent (1982). ORANI: A Multisectoral Model of the Australian Economy. Amsterdam: North-Holland.

Guilhoto, J.J.M. (1986). A Model for Economic Planning and Analysis for the Brazilian Economy. Ph.D. Thesis. University of Illinois.

Guilhoto, J.J.M. (1995). Um Modelo Computável de Equilíbrio Geral para Planejamento e Análise de Políticas Agrícolas (PAPA) na Economia Brasileira. Tese de Livre Docência. Departamento de Economia e Sociologia Rural - ESALQ - USP.

Harrison, W.J., e K.R. Pearson (1994a). "An Introduction to GEMPACK". GEMPACK Document GPD-1. Impact Project.

Harrison, W.J., and K.R. Pearson (1994b). "User's Guide to TABLO, GEMSIM and TABLOGenerated Programs". GEMPACK Document GPD-2. Impact Project.

Johansen, L. (1974). A Multi-Sectoral Study of Economic Growth. Second Edition. Amsterdam: North-Holland.

Pearson, K.R. (1991). "Solving Nonlinear Economic Models Accurately via a Linear Representation”. Impact Preliminary Working Paper. No. IP-55. Melbourne (July), pp. 39. 
Pearson, K.R., and R.J. Rimmer (1983). "Sparce Matrix Methods for Computable General Equilibrium Models of the Johansen Class." Impact Project Preliminary Working Paper. N. OP-43.

Powell, A.A. (1985). "Short Run Applications of ORANI: An Impact Project Perspective." Australian Economic Papers, 24, June, pp. 37-53.

Powell, A.A., R.J. Cooper, and K.R. McLaren (1983). "Macroeconomic Closure in Applied General Equilibrium Modeling: Experience from ORANI and Agenda for Further Research." Impact Project Preliminary Working Paper. N. IP-19.

Rimmer, R.J. (1981). "Elimination of Linearization Errors Which Arise in the Solution of a General Equilibrium Model Using Johansen's Approximation." Impact Project Preliminary Working Paper. N. OP-33. 